\title{
Performance of Genotypic Tools for Prediction of Tropism in HIV-1 Subtype C V3 Loop Sequences
}

\author{
Soham Gupta ${ }^{a, c}$ Ujjwal Neogi ${ }^{c}$ Hiresave Srinivasa ${ }^{a}$ Anita Shet ${ }^{b}$ \\ ${ }^{a}$ Division of Clinical Virology, Department of Microbiology, and ${ }^{b}$ Department of Pediatrics, St. John's Medical \\ College Hospital, Bangalore, India; ' Division of Clinical Microbiology, Department of Laboratory Medicine, \\ Karolinska Institutet, Stockholm, Sweden
}

\section{Key Words}

HIV-1 subtype C - Genotypic tropism testing - R5-tropic .

X4-tropic · V3 loop · Phenotype

\begin{abstract}
Currently, there is no consensus on the genotypic tools to be used for tropism analysis in HIV-1 subtype C strains. Thus, the aim of the study was to evaluate the performance of the different V3 loop-based genotypic algorithms available. We compiled a dataset of 645 HIV-1 subtype C V3 loop sequences of known coreceptor phenotypes (531 R5-tropic/non-syncytium-inducing and 114 X4-tropic/R5X4-tropic/syncytiuminducing sequences) from the Los Alamos database (http:// www.hiv.lanl.gov/) and previously published literature. Coreceptor usage was predicted based on this dataset using different software-based machine-learning algorithms as well as simple classical rules. All the sophisticated machinelearning methods showed a good concordance of above $85 \%$. Geno2Pheno (false-positive rate cutoff of 5-15\%) and CoRSeqV3-C were found to have a high predicting capability in determining both HIV-1 subtype C X4-tropic and R5-tropic strains. The current sophisticated genotypic tropism tools based on V3 loop perform well for tropism prediction in HIV1 subtype $C$ strains and can be used in clinical settings.
\end{abstract}

(c) 2015 S. Karger AG, Basel (c) 2015 S. Karger AG, Base

0300-5526/15/0581-0001\$39.50/0
CCR5 antagonists bind to the CCR5 coreceptor and block the entry of R5-tropic (using the CCR5 coreceptor only) strains. However, these drugs are ineffective against HIV-1 strains that use CXCR4 coreceptors (X4-tropic) or both CCR5 and CXCR4 coreceptors (dual-tropic) for their entry into the host cell [1]. Thus, the major caveat associated with initiating CCR5 antagonist-based therapy is to perform HIV coreceptor tropism prior to its use. HIV-1 coreceptor tropism can be determined by both phenotypic and genotypic methods. Although phenotypic methods are considered to be more reliable, they are limited by higher cost and turnaround time, and more specialized infrastructure [2]. Further, even this 'gold standard' has shortcomings for clinical validation [2].

On the other hand, genotypic tropism testing based on V3 loop sequencing combined with bioinformatic tools is well suited for routine clinical laboratories [3]. There are several genotypic tropism methods available, ranging from simple methods, such as the $11 / 25$ rule, a charge rule based on the amino acid side chains, to more complex statistical models like position-specific scoring matrices (PSSM) and support vector machines (Geno2Pheno; distant segments kernel) [4]. All these machine-learning methods are based on trained datasets available, and most of them have been developed based on the data available from genetic characteristics of HIV-1 subtype B [5]. In

\section{KARGER 125}

E-Mail karger@karger.com www.karger.com/int
Soham Gupta, $\mathrm{PhD}$

Division of Clinical Virology, Department of Microbiology

St. John's Medical College

Bangalore 560034 (India)

E-Mail soham.micro@gmail.com 
Table 1. Site-specific amino acid frequencies in the V3 loop of the 531 R5-tropic/NSI and 114 X4/R5X4-tropic/SI HIV-1 subtype C database sequences

\begin{tabular}{|c|c|c|c|c|c|c|c|c|c|c|c|c|c|}
\hline & \multicolumn{13}{|c|}{ AA position } \\
\hline $\mathrm{X} 4 / \mathrm{R} 5 \mathrm{X} 4 / \mathrm{SI}$ & $\mathrm{C}_{100}$ & $\begin{array}{l}\mathrm{T}_{75.4} \\
\mathrm{I}_{7.9} \\
\mathrm{M}_{6.1} \\
\mathrm{~A}_{3.5} \\
\mathrm{~V}_{2.6} \\
\mathrm{G}_{1.8} \\
\end{array}$ & $\mathrm{R}_{100}$ & $\mathrm{P}_{99.1}$ & $\begin{array}{l}\mathrm{N}_{47.4} \\
\mathrm{G}_{36.8} \\
\mathrm{D}_{5.3} \\
\mathrm{Y}_{5.3} \\
\mathrm{~S}_{3.5}\end{array}$ & $\begin{array}{l}\mathrm{N}_{86} \\
\mathrm{Y}_{5.3} \\
\mathrm{~S}_{3.5} \\
\mathrm{I}_{2.6} \\
\mathrm{~K}_{2.6}\end{array}$ & $\begin{array}{l}\mathrm{N}_{72.8} \\
\mathrm{~K}_{10.5} \\
\mathrm{~T}_{7} \\
\mathrm{H}_{2.6} \\
\mathrm{~S}_{1.8}\end{array}$ & $\begin{array}{l}\mathrm{T}_{70.2} \\
\mathrm{I}_{11.4} \\
\mathrm{~K}_{11.4} \\
\mathrm{R}_{5.3}\end{array}$ & $\begin{array}{l}\mathrm{R}_{78.9} \\
\mathrm{I}_{7.9} \\
\mathrm{~S}_{4.4} \\
\mathrm{E}_{1.8} \\
\mathrm{~K}_{1.8} \\
\mathrm{~N}_{1.8} \\
\end{array}$ & $\mathrm{M}_{5.3}$ & $\begin{array}{l}\mathrm{K}_{66.7} \\
\mathrm{R}_{28.9} \\
\mathrm{~T}_{2.6} \\
\mathrm{Q}_{1.8}\end{array}$ & $\begin{array}{l}\mathrm{S}_{58.8} \\
\mathrm{R}_{26.3} \\
\mathrm{G}_{7} \\
\mathrm{~N}_{3.5} \\
\mathrm{H}_{1.8}\end{array}$ & $\begin{array}{l}\mathrm{I}_{49} \\
\mathrm{~V}_{38.6} \\
\mathrm{M}_{5.3} \\
\mathrm{~L}_{4.4} \\
\mathrm{~A}_{1.8}\end{array}$ \\
\hline R5/NSI & $\begin{array}{l}\mathrm{R}_{96.2} \\
\mathrm{G}_{1.5}\end{array}$ & $\mathrm{I}_{99.2}$ & - & - & $\mathrm{G}_{99.6}$ & $\mathrm{P}_{99.6}$ & $\mathrm{G}_{99.6}$ & $\begin{array}{l}\mathrm{Q}_{98.1} \\
\mathrm{R}_{1.3}\end{array}$ & $\begin{array}{l}\mathrm{T}_{69.9} \\
\mathrm{~A}_{23.9} \\
\mathrm{~V}_{3.8} \\
\mathrm{~S}_{1.9}\end{array}$ & $\begin{array}{l}\mathrm{F}_{96.6} \\
\mathrm{Y}_{1.3} \\
\mathrm{~L}_{1.1}\end{array}$ & $\begin{array}{l}\mathrm{Y}_{84.7} \\
\mathrm{~F}_{14.7}\end{array}$ & $\begin{array}{l}\mathrm{A}_{93.8} \\
\mathrm{~T}_{3.8} \\
-{ }_{1.3}\end{array}$ & $\begin{array}{l}\mathrm{T}_{93.6} \\
\mathrm{~N}_{2.8} \\
\mathrm{M}_{1.1} \\
\mathrm{~A}_{1.1} \\
\end{array}$ \\
\hline X4/R5X4/SI & $\begin{array}{l}\mathrm{R}_{79.8} \\
\mathrm{G}_{10.5} \\
\mathrm{~K}_{8.8}\end{array}$ & $\begin{array}{l}\mathrm{I}_{93.9} \\
\mathrm{~L}_{3.5}\end{array}$ & $\mathrm{G}_{22.8}$ & $\begin{array}{l}\mathrm{I}_{21.1} \\
\mathrm{~V}_{1.8}\end{array}$ & $\mathrm{G}_{100}$ & $\begin{array}{l}\mathrm{P}_{71.1} \\
\mathrm{R}_{24.6}\end{array}$ & $\begin{array}{l}\mathrm{G}_{94.7} \\
\mathrm{R}_{4.4}\end{array}$ & $\begin{array}{l}\mathrm{Q}_{52.6} \\
\mathrm{R}_{23.7} \\
\mathrm{H}_{13.2} \\
\mathrm{~L}_{4.4} \\
\mathrm{Y}_{3.5} \\
\mathrm{~K}_{1.8}\end{array}$ & $\begin{array}{l}\mathrm{A}_{44.7} \\
\mathrm{~T}_{43.9} \\
\mathrm{~S}_{6.1} \\
\mathrm{~V}_{2.6}\end{array}$ & $\begin{array}{l}\mathrm{F}_{89.5} \\
\mathrm{~V}_{3.5} \\
\mathrm{I}_{2.6} \\
\mathrm{~L}_{1.8}\end{array}$ & $\begin{array}{l}\mathrm{Y}_{67.5} \\
\mathrm{~F}_{14} \\
\mathrm{H}_{7.9} \\
\mathrm{~V}_{6.1} \\
\mathrm{~L}_{1.8}\end{array}$ & $\begin{array}{l}\mathrm{A}_{75.4} \\
\mathrm{~T}_{10.5} \\
\mathrm{R}_{1.8} \\
\mathrm{~V}_{1.8} \\
-{ }_{10.5}\end{array}$ & $\begin{array}{l}\mathrm{T}_{69.3} \\
\mathrm{R}_{6.1} \\
\mathrm{~K}_{5.3} \\
\mathrm{M}_{3.5} \\
\mathrm{~A}_{1.8} \\
\mathrm{H}_{1.8} \\
\mathrm{~N}_{1.8} \\
-3.5 \\
\end{array}$ \\
\hline $\mathrm{X} 4 / \mathrm{R} 5 \mathrm{X} 4 / \mathrm{SI}$ & $\begin{array}{l}\mathrm{G}_{57} \\
\mathrm{~N}_{15.8} \\
\mathrm{~K}_{12.3} \\
\mathrm{R}_{4.4} \\
\mathrm{E}_{3.5} \\
\mathrm{D}_{2.6} \\
\mathrm{~T}_{2.6}\end{array}$ & $\begin{array}{l}\mathrm{K}_{20.2} \\
\mathrm{~A}_{14.9} \\
\mathrm{G}_{14} \\
\mathrm{R}_{12.3} \\
\mathrm{D}_{8.8} \\
\mathrm{~N}_{6.1} \\
\mathrm{~T}_{6.1} \\
\mathrm{E}_{5.3} \\
\mathrm{Q}_{5.3} \\
\mathrm{H}_{2.6} \\
-2.6\end{array}$ & $\begin{array}{l}\mathrm{I}_{78.9} \\
\mathrm{~V}_{13.2} \\
\mathrm{~T}_{2.6} \\
\mathrm{M}_{1.8} \\
-2.6\end{array}$ & $\begin{array}{l}\mathrm{I}_{64} \\
\mathrm{~K}_{7} \\
\mathrm{~T}_{7} \\
\mathrm{~V}_{6.1} \\
\mathrm{R}_{5.3} \\
\mathrm{G}_{3.5} \\
\mathrm{~L}_{3.5}\end{array}$ & $\mathrm{G}_{3.5}$ & $\begin{array}{l}\mathrm{G}_{92.1} \\
\mathrm{R}_{5.3} \\
\mathrm{D}_{1.8}\end{array}$ & $\begin{array}{l}\mathrm{D}_{82.5} \\
\mathrm{~N}_{14} \\
\mathrm{E}_{1.8} \\
\mathrm{I}_{1.8}\end{array}$ & $\begin{array}{l}\mathrm{I}_{95.6} \\
\mathrm{~L}_{1.8} \\
\mathrm{R}_{1.8}\end{array}$ & $\begin{array}{l}\mathrm{R}_{98.2} \\
\mathrm{Q}_{1.8}\end{array}$ & $\begin{array}{l}\mathrm{Q}_{82.5} \\
\mathrm{~K}_{13.2} \\
\mathrm{~A}_{2.6} \\
\mathrm{R}_{1.8}\end{array}$ & $\begin{array}{l}\mathrm{A}_{94.7} \\
\mathrm{~S}_{1.8} \\
\mathrm{~T}_{1.8}\end{array}$ & $\begin{array}{l}\mathrm{H}_{71.9} \\
\mathrm{Y}_{14} \\
\mathrm{~F}_{7.9} \\
\mathrm{~S}_{2.6} \\
\mathrm{C}_{1.8}\end{array}$ & $\mathrm{C}_{100}$ \\
\hline
\end{tabular}

Amino acids with frequencies less than 1 are not included. $\mathrm{AA}=$ Amino acid; Ins = insertion; - = deletion. 
Table 2. Performance of genotypic tools in predicting X4 tropism in HIV-1 subtype C V3 loop sequences with known phenotypes

\begin{tabular}{|c|c|c|c|c|c|c|c|}
\hline & & \multicolumn{2}{|l|}{ Phenotype } & \multirow[t]{2}{*}{ Concordance } & \multirow[t]{2}{*}{$\kappa$ value } & \multirow[t]{2}{*}{ Sensitivity } & \multirow[t]{2}{*}{ Specificity } \\
\hline & & $\begin{array}{l}\mathrm{X} 4 / \mathrm{R} 5 \mathrm{X} 4 / \mathrm{SI} \\
(\mathrm{n}=114)\end{array}$ & $\begin{array}{l}\text { R5/NSI } \\
(\mathrm{n}=531)\end{array}$ & & & & \\
\hline \multirow[t]{2}{*}{ Geno2Pheno $_{5 \%}$} & $\mathrm{X} 4$ & 95 & 13 & 95 & 0.83 & 83.3 & 97.6 \\
\hline & R5 & 19 & 518 & & & & \\
\hline \multirow[t]{2}{*}{ Geno2Pheno $_{10 \%}$} & $\mathrm{X} 4$ & 99 & 28 & 93.3 & 0.78 & 86.8 & 94.7 \\
\hline & R5 & 15 & 503 & & & & \\
\hline \multirow[t]{2}{*}{ Geno2Pheno $_{15 \%}$} & $\mathrm{X} 4$ & 100 & 48 & 90.2 & 0.7 & 87.7 & 91 \\
\hline & R5 & 14 & 483 & & & & \\
\hline \multirow[t]{2}{*}{ Geno2Pheno $_{20 \%}$} & $\mathrm{X} 4$ & 104 & 77 & 86.5 & 0.6 & 91.2 & 85.5 \\
\hline & $\mathrm{R} 5$ & 10 & 454 & & & & \\
\hline \multirow[t]{2}{*}{ CoRSeqV3-C } & $\mathrm{X} 4$ & 103 & 42 & 91.8 & 0.75 & 90.4 & 92.1 \\
\hline & R5 & 11 & 489 & & & & \\
\hline \multirow{2}{*}{$\overline{\mathrm{C}}$-PSSM$_{\text {SINSI }}$} & $\mathrm{X} 4$ & 99 & 70 & 86.8 & 0.62 & 86.8 & 86.8 \\
\hline & $\mathrm{R} 5$ & 15 & 461 & & & & \\
\hline \multirow[t]{2}{*}{$\mathrm{B}-\mathrm{PSSM}_{\mathrm{X} 4 \mathrm{R} 5}$} & $\mathrm{X} 4$ & 87 & 33 & 90.7 & 0.68 & 76.3 & 93.8 \\
\hline & $\mathrm{R} 5$ & 27 & 498 & & & & \\
\hline \multirow[t]{2}{*}{$\bar{B}_{-P S S M}^{\text {SINSI }}$} & $\mathrm{X} 4$ & 77 & 33 & 89.2 & 0.62 & 67.5 & 93.8 \\
\hline & R5 & 37 & 498 & & & & \\
\hline \multirow[t]{2}{*}{ ds kernel } & $\mathrm{X} 4$ & 82 & 2 & 94.7 & 0.8 & 71.9 & 99.6 \\
\hline & R5 & 32 & 529 & & & & \\
\hline \multirow[t]{2}{*}{$11 / 25$ rule } & $\mathrm{X} 4$ & 55 & 12 & 89 & 0.55 & 48.2 & 97.7 \\
\hline & R5 & 59 & 519 & & & & \\
\hline \multirow[t]{2}{*}{$11 / 24 / 25$ rule } & $\mathrm{X} 4$ & 66 & 18 & 89.8 & 0.61 & 57.9 & 96.6 \\
\hline & $\mathrm{R} 5$ & 48 & 513 & & & & \\
\hline \multirow[t]{2}{*}{ Net charge $\geq+5$} & $\mathrm{X} 4$ & 106 & 159 & 74.1 & 0.42 & 93 & 70.1 \\
\hline & R5 & 8 & 372 & & & & \\
\hline \multirow[t]{2}{*}{ Net charge $\geq+6$} & $\mathrm{X} 4$ & 86 & 22 & 92.2 & 0.73 & 75.4 & 95.9 \\
\hline & R5 & 28 & 509 & & & & \\
\hline \multirow[t]{2}{*}{ Raymond's rule $^{a}$} & $\mathrm{X} 4$ & 92 & 30 & 91.9 & 0.73 & 80.7 & 94.4 \\
\hline & $\mathrm{R} 5$ & 22 & 501 & & & & \\
\hline \multirow[t]{2}{*}{ Garrido's rule $^{b}$} & $\mathrm{X} 4$ & 106 & 162 & 73.6 & 0.41 & 93 & 69.5 \\
\hline & R5 & 8 & 369 & & & & \\
\hline
\end{tabular}

\footnotetext{
Concordance, sensitivity and specificity of $>90 \%$ are highlighted in italics. ds $=$ Distant segments.

a One of the following criteria is required for predicting CXCR4 coreceptor usage: (1) $11 \mathrm{R} / \mathrm{K}$ and/or $25 \mathrm{~K}$ in V3; (2) $25 \mathrm{R}$ in V3 and a net charge of $\geq+5$ and (3) a net charge of $\geq+6$.

${ }^{b} 11 / 25$ or a net charge of $\geq+5$.
}

spite of the presence of several methods that may be used to determine HIV-1 tropism, there still seems to exist a considerable discrepancy among these tropism tools. Furthermore, though the validity of these tests is well studied in subtype B strains, data are lacking for subtype $\mathrm{C}$ strains which account for more than $60 \%$ of the infection worldwide; subtype $\mathrm{C}$ is, moreover, the most predominant subtype in India. Thus, there is no clear consensus on the appropriate tool for routine clinical use in subtype C-predominant settings.

Genotypic Tools for Prediction of Tropism in HIV-1 Subtype C V3 Loop Sequences
Thus, we aimed to evaluate the performance of the different V3 loop-based genotypic algorithms available in predicting coreceptor usage in a dataset of HIV-1 subtype C V3 loop sequences with known biological phenotypes.

We compiled a dataset of 645 HIV-1 subtype C V3 loop sequences of known coreceptor phenotypes based on coreceptor-transfected cell lines for CCR 5 or CXCR4 coreceptor usage or MT-2 cells for non-syncytium-inducing (NSI) and syncytium-inducing (SI) properties, from the Los Alamos database (http://www.hiv.lanl.gov/) and from previously published literature [6-9]. Sequenc- 
es containing \#, \$ or * were eliminated from the dataset. Multiple sequences from a single patient were included only when the amino acid sequences were unique. 531 R5-tropic/NSI V3 sequences (from 365 patients) and 114 X4-tropic/R5X4-tropic/SI sequences (from 69 patients) were included. The frequency of amino acid substitutions at each site of the V3 loop for both the R5-tropic and X4tropic dataset is shown in table 1 . The coreceptor usage was predicted on this dataset using the different softwarebased algorithms, which comprised Geno2Pheno ${ }_{\text {coreceptor }}$ (http://coreceptor.bioinf.mpi-inf.mpg.de/) at false-positive rate cutoffs of 5, 10, 15 and 20\%, PSSM (http://indra. mullins.microbiol.washington.edu/webpssm/), both X4/ R5 and SI/NSI matrices for subtype B (B-PSSM $\mathrm{X}_{4 \mathrm{R} 5}$ and B-PSSM ${ }_{\text {SINSI, }}$ respectively) and SI/NSI matrices for sub-

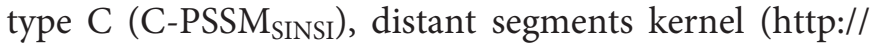
genome.ulaval.ca/hiv-dskernel/), CoRSeqV3-C (http:// tools.burnet.edu.au/coreceptor/) specific for subtype C, as well as classical models like the V3 loop net charge rule, the $11 / 25$ rule and the $11 / 24 / 25$ rule (based on positive charge at these positions) and a combination of simple rules like Garrido's rule (11/25 or a net charge of $\geq+5)$ [10] and Raymond's rule (any of the following criteria: 11 $\mathrm{R} / \mathrm{K}$ and/or $25 \mathrm{~K}$ in $\mathrm{V} 3 ; 25 \mathrm{R}$ in $\mathrm{V} 3$ and a net charge of $\geq+5$ or a net charge of $\geq+6$ ) [11].

The concordance, sensitivity and specificity of all the algorithms are depicted in table 2 . The concordance between the tropism results obtained by the genotypic algorithms and the HIV-1 subtype $C$ phenotypes ranged from 73.6 to $95 \%$, depending on the genotypic tools used. All the sophisticated machine-learning methods showed a good concordance of above $85 \%$. The best concordance was obtained with Geno2Pheno5\% (95\%). Among the simple rules, net charge $\geq+6$ and Raymond's rule showed a concordance of $>90 \%$. In terms of sensitivity of detecting X4 tropism, though Garrido's rule (93\%) and the net charge $\geq+5$ rule $(93 \%)$ were among the most sensitive tools, they severely lacked specificity (69.5 and $70.1 \%$, respectively). Among the other tools, CoRSeqV3-C showed the highest sensitivity (90.4\%), without compromising the specificity (92.1\%). Geno2Pheno at the recommended false-positive rate cutoff of $10 \%$ as per the European guideline of HIV-1 tropism testing also showed a high sensitivity (86.8\%) and specificity (94.7\%). The other tools that showed both good sensitivity and specificity are Geno2Pheno ${ }_{5 \%}$ (83.3/97.6\%), Geno2Pheno ${ }_{15 \%}$ (87.7/91\%), Geno2Pheno $20 \%$ (91.2/85.5\%), C-PSSM (86.8/86.8\%) and Raymond's rule (80.7/94.4\%).

Currently, there is no consensus on the genotypic tools to be used for tropism analysis. European virologists have suggested in their guidelines that the use of Geno2Phe$\mathrm{no}_{10 \%}$, which is a well-validated tool, may be acceptable [2]. Other than Geno2Pheno, the most widely validated tool for subtype C is C-PSSM [12]. Prior to C-PSSM, $\mathrm{PSSM}_{\mathrm{X} 4 \mathrm{R} 5}$ and $\mathrm{PSSM}_{\mathrm{SINSI}}$ matrices were developed by Jensen et al. [13] based on subtype B V3 loop sequences. In view of a poor performance of the subtype B-specific PSSM in subtype C strains, a subtype C-specific C-PSSM was developed by the same group [12]. The difference in predictive performance of both subtype B- and subtype $\mathrm{C}$-specific PSSM is evident in our observation. Though the overall concordance of C-PSSM was lower than that of B-PSSM, C-PSSM showed a better sensitivity in picking up $\mathrm{X} 4$ tropism in subtype $\mathrm{C}$ strains. A recent study based on database sequences has shown a 90 and $89 \%$ sensitivity of detecting X4-tropic strains by Geno2Phe$\mathrm{no}_{10 \%}$ and C-PSSM, respectively [14]. This was moderately higher than what we have observed. In our dataset, both Geno2Pheno ${ }_{5 \%}$ and Geno2Pheno ${ }_{10 \%}$ showed a much better concordance and specificity and a similar sensitivity to that of C-PSSM. Our results are highly similar to the values obtained by Raymond et al. [15] on subtype C live samples from Malawi and France. In their study, Raymond et al. [15] found the combined 11/25 and net charge rule to have a superior sensitivity (93.3\%) and specificity (96.4\%) compared to other tools. However, in our study, their rule lacked sensitivity. In our dataset of X4-tropic strains, a good interassay concordance of $93 \%$ between Geno2Pheno $_{10 \%}$ and C-PSSM was observed.

Contrary to what had been observed in subtype C strains, earlier studies on subtype B strains observed Geno2Pheno (sensitivity ranging from 88 to $97 \%$ ) to outperform B-PSSM (sensitivity ranging from 69 to $94 \%$ ) in terms of sensitivity $[10,11,16,17]$. But in these four studies on subtype B strains, Geno2Pheno (specificity ranging from 51 to $93 \%$ ) lacked specificity compared to B-PSSM (81-100\%). This subtype B-specific B-PSSM showed poor sensitivity $(<80 \%)$ when analyzed against subtype C strains as compared to its subtype C-specific counterpart (C-PSSM), as both have been trained against their respective subtypes. However, Raymond et al. [15] suggested that both HIV-1 subtype C and B viruses share the genotypic determinants of coreceptor usage mainly located in the V3 loop and, thus, algorithms trained against subtype $B$ strains perform equally well in subtype $C$ strains.

Very recently, another novel genotypic tool specific for subtype C strains (CoRSeqV3-C) has been evaluated against known phenotype datasets by Cashin et al. [18]. In their dataset, they observed a superior sensitivity of CoRSeqV3-C with a specificity comparable to Geno- 
2Pheno and C-PSSM [18]. We made a very similar observation. For a proper clinical evaluation of tropism, it is equally important to look into the specificity of a test to rule out false $\mathrm{X} 4$ prediction, along with the sensitivity of determining X4 tropism. Thus, among all the tools, both Geno2Pheno (false-positive rate cutoff of 5-15\%) and CoRSeqV3-C were found to have a high predicting capability in determining both HIV-1 subtype C X4-tropic and R5-tropic strains.

In conclusion, the current sophisticated genotypic tropism tools based on V3 loop perform well for tropism prediction in HIV-1 subtype C strains and can be used for assessing the option of using CCR5 antagonists in clinical settings. However, there is a need to perform further studies to elucidate additional coreceptor determinants across all the subtypes for making coreceptor determination more robust.

\section{Disclosure Statement}

The authors declare that they have no conflicts of interest.

\section{References}

1 Lobritz MA, Ratcliff AN, Arts EJ: HIV-1 entry, inhibitors, and resistance. Viruses 2010;2: 1069-1105.

-2 Vandekerckhove LP, Wensing AM, Kaiser R, Brun-Vezinet F, Clotet B, De Luca A, Dressler S, Garcia F, Geretti AM, Klimkait T, Korn K, Masquelier B, Perno CF, Schapiro JM, Soriano V, Sonnerborg A, Vandamme AM, Verhofstede C, Walter H, Zazzi M, Boucher CA: European guidelines on the clinical management of HIV-1 tropism testing. Lancet Infect Dis 2011;11:394-407.

- 3 Gupta S, Neogi U, Srinivasa H, Shet A: High concordance of genotypic coreceptor prediction in plasma-viral RNA and proviral DNA of HIV-1 subtype C: implications for use of whole blood DNA in resource-limited settings. J Antimicrob Chemother 2013;68:2003-2006.

- 4 Lengauer T, Sander O, Sierra S, Thielen A, Kaiser R: Bioinformatics prediction of HIV coreceptor usage. Nat Biotechnol 2007;25: 1407-1410.

5 Garrido C, Roulet V, Chueca N, Poveda E, Aguilera A, Skrabal K, Zahonero N, Carlos S, Garcia F, Faudon JL, Soriano V, de Mendoza C: Evaluation of eight different bioinformatics tools to predict viral tropism in different human immunodeficiency virus type 1 subtypes. J Clin Microbiol 2008;46:887-891.

-6 Coetzer M, Cilliers T, Ping LH, Swanstrom R, Morris L: Genetic characteristics of the V3 region associated with CXCR4 usage in HIV-1 subtype C isolates. Virology 2006;356:95105.

7 Dybowski JN, Heider D, Hoffmann D: Prediction of co-receptor usage of HIV-1 from genotype. PLoS Comput Biol 2010;6: e1000743.
8 Michler K, Connell BJ, Venter WD, Stevens WS, Capovilla A, Papathanasopoulos MA: Genotypic characterization and comparison of full-length envelope glycoproteins from South African HIV type 1 subtype C primary isolates that utilize CCR5 and/or CXCR4 AIDS Res Hum Retroviruses 2008;24:743751.

-9 Choge I, Cilliers T, Walker P, Taylor N, Phoswa M, Meyers T, Viljoen J, Violari A, Gray G, Moore PL, Papathanosopoulos M, Morris L: Genotypic and phenotypic characterization of viral isolates from HIV-1 subtype C-infected children with slow and rapid disease progression. AIDS Res Hum Retroviruses 2006; 22:458-465.

10 Seclen E, Garrido C, Gonzalez Mdel M, Gonzalez-Lahoz J, de Mendoza C, Soriano V, Poveda E: High sensitivity of specific genotypic tools for detection of X4 variants in antiretroviral-experienced patients suitable to be treated with CCR5 antagonists. J Antimicrob Chemother 2010;65:1486-1492.

11 Raymond S, Delobel P, Mavigner M, Cazabat M, Souyris C, Sandres-Saune K, Cuzin L, Marchou B, Massip P, Izopet J: Correlation between genotypic predictions based on V3 sequences and phenotypic determination of HIV-1 tropism. AIDS 2008;22:F11-F16.

12 Jensen MA, Coetzer M, van 't Wout AB, Morris L, Mullins JI: A reliable phenotype predictor for human immunodeficiency virus type 1 subtype $\mathrm{C}$ based on envelope $\mathrm{V} 3$ sequences. J Virol 2006;80:4698-4704.

13 Jensen MA, Li FS, van 't Wout AB, Nickle DC, Shriner D, He HX, McLaughlin S, Shankarappa R, Margolick JB, Mullins JI: Improved coreceptor usage prediction and genotypic monitoring of R5-to-X4 transition by motif analysis of human immunodeficiency virus type 1 env V3 loop sequences. J Virol 2003;77: 13376-13388.
14 Crous S, Shrestha RK, Travers SA: Appraising the performance of genotyping tools in the prediction of coreceptor tropism in HIV-1 subtype C viruses. BMC Infect Dis 2012;12: 203.

15 Raymond S, Delobel P, Mavigner M, Ferradini L, Cazabat M, Souyris C, Sandres-Saune K, Pasquier C, Marchou B, Massip P, Izopet J: Prediction of HIV type 1 subtype $C$ tropism by genotypic algorithms built from subtype $\mathrm{B}$ viruses. J Acquir Immune Defic Syndr 2010; 53:167-175.

-16 Delgado E, Fernandez-Garcia A, Vega Y, Cuevas T, Pinilla M, Garcia V, Sanchez M, Gonzalez M, Sanchez AM, Thomson MM, Perez-Alvarez L: Evaluation of genotypic tropism prediction tests compared with in vitro co-receptor usage in HIV-1 primary isolates of diverse subtypes. J Antimicrob Chemother 2012;67:25-31.

-17 Chueca N, Garrido C, Alvarez M, Poveda E, de Dios Luna J, Zahonero N, HernandezQuero J, Soriano V, Maroto C, de Mendoza C, Garcia F: Improvement in the determination of HIV-1 tropism using the V3 gene sequence and a combination of bioinformatic tools. J Med Virol 2009;81:763-767.

18 Cashin K, Gray LR, Jakobsen MR, Sterjovski J, Churchill MJ, Gorry PR: CoRSeqV3-C: a novel HIV-1 subtype C specific V3 sequence based coreceptor usage prediction algorithm. Retrovirology 2013;10:24.
Genotypic Tools for Prediction of Tropism in HIV-1 Subtype C V3 Loop Sequences 